\title{
Factors Associated with Dental Caries of Permanent First Molars among Thai Primary Schoolchildren
}

\author{
Septika PRISMASARI and Songchai THITASOMAKUL *
}

Department of Preventive Dentistry, Children Oral Health Promotion and Caries Prevention Research Unit, Faculty of Dentistry, Prince of Songkla University, Songkhla 90110, Thailand

('Corresponding author's e-mail: songchai.t@psu.ac.th)

Received: 23 May 2017, Revised: 19 February 2018, Accepted: 6 March 2018

\begin{abstract}
Permanent first molars are the most vulnerable teeth to dental caries. This study aimed to assess the association among the eruption stage of permanent first molars, demographic, socio-economic, tooth brushing behaviors and fluoride used among 6 - 8 years old schoolchildren of Tessaban Primary School in Hat Yai Municipality. Cross-sectional data on eruption stage of permanent first molars, demographic, socio-economic, tooth brushing behavior and fluoride used were assembled from 346 children-caretaker pairs using structured-questionnaire. Caries status was clinically examined using modified criteria from WHO. Fixed effect random intercept logistic regression was used to estimate the magnitude independent association between variables and caries status based on variability within-subject. The prevalence of dental caries in permanent first molars was $43.6 \%$, while the caries experience indexed as Decayed, Missing, and Filling Teeth (DMFT) was $1.00 \pm 1.36$. Children who brush irregularly at night, share tooth brush among family member and have deciduous caries significantly inclined to have higher caries in the permanent first molars than those who did not. These findings should be noticed to take appropriate treatment and preventive measures in this age group.
\end{abstract}

Keywords: Dental caries, permanent first molars, primary schoolchildren, risk factors, brushing behavior

\section{Introduction}

Dental caries is of worldwide concern because it occurs almost in every age group. Nationwide, about $52.3 \%$ of 12-year-old children in Thailand were reported to be affected by dental caries in permanent dentition. The mean Decayed, Missing, and Filling Teeth (DMFT) index was 1.34 consisted of $55 \%$ decayed, $4 \%$ missing and $72 \%$ filled teeth [1]. A high dental caries of 12-year-old children is a result of cumulative dental caries incident at 6 years old. Children who present with caries in the early permanent molars were more likely to develop caries progression years later than those who did not [2]. Further, untreated dental caries in children might affect their physical development and their social, educational and emotional quality of life and their academic performance $[3,4]$.

Several risk factors of caries in permanent molars such as plaque accumulation as well as pit and fissure morphology have been published [5-7]. Partially eruption stage of molars promoted higher accumulation of occlusal plaque and were 63.6 times more susceptible to caries progression than molars in fully erupted stage [8]. Schoolchildren aged 6 - 9 years old are the highest risk group for increasing dental caries in early permanent dentition since the permanent first molars start to erupt in this age group [9]. Decay and loss of permanent molars at an early age could affect the mastication system which leads to malnutrition and increases the need for complex and costly treatment [10].

Brushing alone is mechanical way to break and remove plaque formation. By adding to fluoridated paste, the process becomes chemical by strengthening hydroxyapatite formation $[11,12]$. However, the causes of dental caries are varying due to the complexity of environment and may involve psycho-social 
http://wjst.wu.ac.th

aspects [13]. In the last decade, socio-economic and demographic characteristics have been reviewed and investigated both in cross-sectional and longitudinal studies as factors affecting dental caries in children [2,14-16]. Nevertheless, the results were varied since they came from different countries.

The permanent first molars are the most vulnerable caries during their eruption stage, particularly the occlusal pit and fissure surfaces [5,17]. The permanent first molar was also reported to be frequently extracted in 11 - 20 years old children due to caries and endodontic condition, thus this can affect second and third molars development $[18,19]$.

In Thailand, few studies about demographic and socio-economic variables as risk factors of dental caries had been published [20-23]. However, those studies were conducted in older children (12 - 15 years old) who had fully erupted permanent first molars. Other study in southern region focused on early childhood or infant caries risk factors [24]. None of the studies reported about associated factors of dental caries in early development of permanent first molars. Therefore, this study aimed to identify the eruption stage of permanent first molars, demographic, socio-economic, tooth brushing behaviors and fluoride used associated with caries prevalence of permanent first molars in the early eruption stage.

\section{Materials and methods}

This research was a cross-sectional study. The study was conducted in a primary school in Hat Yai municipality, Songkhla, Southern Thailand. To cover the age that is timing of first permanent molars eruption, children grade 1 and 2 of primary school and their caretaker were recruited as sample after receiving an explanation and agreed to participate in the study by signing a consent form. The sample size was estimated by using the formula of one-sample situation for cross sectional study [25] with $52 \%$ proportion of subject who get the disease, $95 \%$ confidence interval and $5 \%$ of absolute precision, it required 384 of sample size. To avoid ethical and equality issue, all 450 children with permitted consent in the grade 1 and 2 were examined. Ethical approval was obtained from the Research Ethical Committee, Faculty of Dentistry, Prince of Songkla University.

The dental examination was carried out at the school hall by 2 examiners using mouth mirror and probe, if appropriate, under artificial light on the portable dental chair. Eruption stage was examined using 5 criteria from Carvalho et al. [26] which was then modified into 3 categories i.e. partially erupted, occlusal surfaces fully erupted, and fully erupted. Occlusal plaque was observed by coloring the surface using erythrosine $6 \%$ and was measured using criteria from Addy et al. [27]. The criteria then was modified to be low, moderate and high status. Meanwhile, the dentition status of permanent first molars was obtained using modified criteria from WHO (WHO Oral Health Surveys 2013). The modification broadened the caries criteria as follows:

$0(\mathrm{D} 0)=$ Sound. Normal enamel surface, no evidence of treated/untreated clinical caries and no restoration.

1 (D1) = Initial caries/white spot. Whitish or yellowish opaque with intact enamel surfaces.

2 (D2) = Enamel caries. Carious opacity (white spot lesion) and/or brown carious discoloration that wider than the natural fissure/fossa, show sign of enamel defect but no wall or fall involve dentin.

$3(\mathrm{D} 3)=$ Dentin caries. Lesion show distinct dark shadow from dentin or distinct cavity with visible dentin.

4 (D4) $=$ Caries exposed pulp. Deep cavity with pulp involvement.

Calibration between 2 examiners (inter-examiners) and within-examiner (intra-examiner) was performed and expressed by Kappa statistics as recommended by WHO. The unweighted kappa value of inter-examiner was 0.72 for caries status, 0.63 for eruption stage status, 0.73 for occlusion status and 0.61 for occlusal plaque status. Meanwhile the intra-examiners Kappa for caries status were 0.84 and 0.90, respectively. Intra-examiner for occlusal plaque was not conducted due to unstable plaque status among children in the different time. Intra-examiner calibration of eruption stage and occlusion status were not conducted due to limited time in the field.

Primary teeth or deciduous caries experience (deft) was also recorded. Distinct cavity or dark shadow of dentin caries was recorded as decay (dt). Filling or restoration without decay was recorded as filled teeth (ft), whereas extracted teeth due to caries reason was described as extracted teeth (et). 
http://wjst.wu.ac.th

The caretakers of children were interviewed by telephone using structured-questionnaire. It was developed by the researcher based on literature review containing 21 questions related to demographic (age, gender, religion, relationship status with caretaker), socio-economic (educational level, family income), tooth brushing behavior (brushing time, brushing frequency, sharing toothbrush) and snacking frequency of the children, mother's practices of children's tooth brushing practice and mother's confidence in preventing children from dental caries. The content and language used in the questionnaire were validated by 3 experts from Faculty of Dentistry, Prince of Songkla University with content validity index (CVI) score 0.88. The main outcome in this study was caries prevalence at child level (DMFT) that was dichotomized to be caries free $(\mathrm{DMFT}=0)$ and caries affected (DMFT $\geq 1)$. In addition, the severity of caries in the children was also described into D2-4MFT and D3-4MFT.

The data were checked for accuracy and entered in the computer using STATA. Frequency was calculated for categorical data, while mean and standard deviation (SD) were calculated for continuous data. The cumulative caries status in each molar was calculated to sum the DMFT. Children were divided into 2 groups based on existence of caries in the permanent first molars (carries-affected and caries-free) and cross-tabulated against variables. Chi-square was used to evaluate the statistical significance association (univariate model) between each variables and caries-affected permanent first molars. Due to the difference of total permanent first molars among children, fixed effect random intercept logistic regression was used. It is to estimate the magnitude independent association between variables and caries status based on variability within-subject. In the model, child was considered to be the random element and all of variables to have fixed effects. The dependent variable was the caries status of permanent first molars (DMFT $=0$ and DMFT $\geq 1$ ) while all of variables were the independent. The odds ratio (OR) and $95 \%$ confidence intervals were calculated to indicate the strength of association between variables and caries-affected permanent first molars.

\section{Results and discussion}

From 450 children who were examined in this study, 378 child-caretaker pairs were able to complete the interview and dental examination. Thirty-two children were excluded due to unerupted permanent first molars. Three hundred and forty-six children who had completed data and at least had one erupted permanent first molar were analyzed. There is no significant difference in sample characteristics between excluded and included group.

The majority of children in this study aged $7-8$ years old and most of children in this sample had deciduous caries (89.6\%). Among of them were always brushing at morning and never after lunch time, half of them brushing at night, and did not share their tooth brush with their siblings or family members. Whereas, the majority of caretakers were female aged 31 - 50 years old with family income $\geq$ USD 427 , more than $60 \%$ were the mother of children with secondary/high school education level. Most of them never supervised and checked their children's tooth brushing performance, irregularly looked into children's mouth and felt not confident in preventing children from dental caries (Table 1). 
Table 1 Demographic and socio-economic characteristics of children and caretakers $(n=346)$.

\begin{tabular}{|c|c|c|c|}
\hline Variables of Children & $\mathbf{N}(\%)$ & Variables of Caretakers & $\mathbf{N}(\%)$ \\
\hline Age $($ Mean \pm SD), years old & $6.85 \pm 0.70$ & Age $($ Mean $\pm S D)$, years old & $38.25 \pm 8.48$ \\
\hline $5-6$ & $112(32.7)$ & $\leq 30$ & $53(15.3)$ \\
\hline $7-8$ & $231(66.7)$ & $31-50$ & $268(77.4)$ \\
\hline $9-10$ & $3(0.6)$ & $\geq 51$ & $25(7.3)$ \\
\hline Gender & & Gender & \\
\hline Boy & $182(52.6)$ & Male & $80(23.2)$ \\
\hline Girl & $164(47.4)$ & Female & $266(76.8)$ \\
\hline Religion & & Relationship & \\
\hline Buddhism & $221(63.8)$ & Mother & $229(66.2)$ \\
\hline Muslim & $125(36.2)$ & Father/other relation & $117(33.8)$ \\
\hline Deciduous caries & & Education level & \\
\hline $\operatorname{deft} \geq 1$ & $310(89.6)$ & Uneducated/primary & $76(22.0)$ \\
\hline \multirow[t]{2}{*}{$\operatorname{deft}=0$} & $36(10.4)$ & Secondary/high school & $215(62.1)$ \\
\hline & & University/higher & $55(15.9)$ \\
\hline Brushing in the morning & & Family income per month & \\
\hline Never/Sometimes & $56(16.2)$ & $<$ USD 427 & $123(35.5)$ \\
\hline Always & $290(83.8)$ & $\geq$ USD 427 & $223(64.5)$ \\
\hline Brushing after lunch & & Supervision during brushing & \\
\hline Never/Sometimes & $310(89.6)$ & Never/Sometimes & $273(79.0)$ \\
\hline Always & $36(10.4)$ & Always & $73(21.0)$ \\
\hline Brushing in the night & & Checking after brushing & \\
\hline Never/Sometimes & $160(46.3)$ & Never/Sometimes & $296(85.6)$ \\
\hline Always & $186(53.7)$ & Always & $50(14.4)$ \\
\hline Sharing toothbrush & & Checking child's teeth & \\
\hline Yes & $13(3.7)$ & Never/sometimes & $241(69.7)$ \\
\hline No & $333(96.3)$ & Regularly & $105(30.3)$ \\
\hline Snacking between meals & & Confidence of caretaker & \\
\hline Yes & $136(39.3)$ & Not confident & $250(72.3)$ \\
\hline No & $210(60.7)$ & Confident & $96(27.7)$ \\
\hline \multicolumn{4}{|l|}{ Snacking before bedtime } \\
\hline Yes & $92(26.6)$ & & \\
\hline No & $254(73.4)$ & & \\
\hline \multicolumn{4}{|l|}{ Eruption stage } \\
\hline Fully erupted & $5(1.4)$ & & \\
\hline Occlusal surface fully erupted & $185(53.5)$ & & \\
\hline Partially erupted & $156(45.1)$ & & \\
\hline \multicolumn{4}{|l|}{ Occlusal plaque status } \\
\hline Low & $31(9.0)$ & & \\
\hline Moderate & $171(49.4)$ & & \\
\hline High & $144(41.6)$ & & \\
\hline
\end{tabular}

The prevalence of caries-free in this sample was $56.4 \%$. The level of decayed severity was presented in D1-4MFT, D2-4MFT and D3-4MFT, respectively. The prevalence of severe decay (D34MFT) was up to $14.6 \%$ (Table 2). In addition, when analyzed at each individual tooth, the status of the teeth presented in the Table 3. The results showed that severe caries experience was $5.8 \%$ and most of them were in decayed status (80 - $95 \%$ ), only few of them were filled (Table 3). 
Table 2 Dentition status of permanent first molars in 5 - 8 years old children $(\mathrm{N}$ of children $=346)$.

\begin{tabular}{lcc}
\hline Categories & N of children (\%) & Mean \pm SD \\
\hline Caries free & $195(56.4)$ & $2.50 \pm 1.45$ \\
D1-4MFT & $151(43.6)$ & $1.00 \pm 1.36$ \\
D2-4MFT & $115(33.2)$ & $0.69 \pm 1.16$ \\
D3-4MFT & $49(14.6)$ & $0.22 \pm 0.61$ \\
\hline
\end{tabular}

Table 3 Dentition status of permanent first molars $(\mathrm{N}$ of teeth $=997)$.

\begin{tabular}{lccc}
\hline Categories & N of teeth (\%) & Decayed teeth (DT, \%) & Filled teeth (FT, \%) \\
\hline Caries free & $952(73.4)$ & - & - \\
D1-4MFT & $345(26.6)$ & $330(95.6)$ & $15(4.3)$ \\
D2-4MFT & $239(18.4)$ & $224(93.7)$ & $15(6.2)$ \\
D3-4MFT & $76(5.8)$ & $61(80.3)$ & $15(19.3)$ \\
\hline
\end{tabular}

In univariate model, it is found that deciduous caries (deft), brushing after lunch, age of caretaker and caretaker's awareness by checking after brushing were significantly associated with caries in permanent first molars. Whereas, the result of fixed effects random intercepts logistic regression model of caries prevalence in permanent first molars is presented as shown in the Table 4. This model showed that regular brushing at night $(\mathrm{OR}=0.41,95 \% \mathrm{CI}=0.187-0.895)$, sharing tooth brush with family members $(\mathrm{OR}=6.28,91 \% \mathrm{CI}=1.055-37.326)$, and having deciduous caries $(\mathrm{OR}=12.54,95 \% \mathrm{CI}=2.780-$ 56.584) were statistically significant associated with high caries prevalence in permanent first molars.

Table 4 Fixed effect random intercept logistic regression of caries in permanent first molars.

\begin{tabular}{lccc}
\hline Variables & Odds ratio & P-value & 95\% CI \\
\hline Brushing at morning (Always) & 0.74 & 0.551 & $0.271-2.005$ \\
Brushing after lunch (Always) & 0.28 & 0.065 & $0.071-1.084$ \\
Brushing at night (Always) & 0.43 & 0.036 & $0.198-0.946$ \\
Sharing tooth brush (Yes) & 6.72 & 0.035 & $1.142-39.525$ \\
Supervision during brushing (Always) & 1.74 & 0.138 & $0.807-4.702$ \\
Snacking between meals (Yes) & 1.03 & 0.935 & $0.476-2.237$ \\
Snacking before bedtime (Yes) & 0.76 & 0.517 & $0.327-1.755$ \\
Deciduous caries (DMFT $\geq 1$ 1) & 12.54 & 0.001 & $2.780-56.584$ \\
Fully erupted occlusal surface of molars & 1.24 & 0.466 & $0.697-2.211$ \\
Fully erupted of molars & 2.59 & 0.134 & $0.747-8.925$ \\
Moderate occlusal plaque status & 1.83 & 0.273 & $0.620-5.417$ \\
Severe occlusal plaque status & 1.31 & 0.649 & $0.007-1.845$ \\
\hline
\end{tabular}

\section{Discussion}

Overall $43.6 \%$ of the children had caries affected in permanent first molars. Regular brushing at night, sharing tooth brush among family members and having deciduous caries was a set of variables found to be associated with dental caries in permanent first molars. The number of participants in this study fulfilled $91.5 \%$ of minimum sample size. The prevalence of permanent teeth caries in early eruption stage ( $6-8$ years old) was not surveyed in the country yet, however, it is still extremely high when compare to $52.3 \%$ of 12 years old children caries-affected [1]. The data from oral health services 
http://wjst.wu.ac.th

records of Hatyai district hospital found that only $5 \%$ of 6 years old children get caries in permanent teeth. Comparing to other similar study [28], this finding shows that the caries prevalence of permanent first molar of the study is high. However, different caries identified criteria used among studies should be concerned.

Previous longitudinal studies revealed that caries in the primary teeth is the strongest factor of caries incidence in permanent teeth [14,29]. This study found association of primary teeth caries and permanent first molars caries that could be their mother or caretakers were less concern in children's oral health, take more cariogenic food and less strict in brushing. Proper prevention in younger age may well arrest the caries progression within permanent erupting development [2].

It was not surprising that regular brushing children in this study get less caries experience. Further, building good oral hygiene habit from earliest stage of eruption will protect the other permanent teeth and make it lasts a life time [30]. Tooth brushing at least twice a day was observed to be an important factor regarding dental caries. It provides a mechanical plaque control by removing accumulated plaque on the tooth surface and then arrests caries progression in enamel and prevents from further dental decay $[11,12]$. However, it was unexpected to see that level of occlusal plaque was not associated with the caries in the present study. This could be a low variation among the sample.

In this study, the majority of children were always brushing at morning before doing daily activities. However, children who always brushed after lunch had a lower prevalence of caries in permanent first molars reflects the importance of brushing after lunch program since the children spend their day time in the school almost every day. Moreover, the supervised tooth brushing in school-based program in Thailand has proven to be an effective way of reducing caries incidence [31].

The other important time to brush is at night, especially before going bed. In this study, children who irregularly brush at night were likely to have higher caries prevalence than those who regularly did that. During sleeping, the flow rate is reduced and acid environment due to acid lactate of cariogenic bacteria metabolism occurs [32]. Brushing at night is advised in order to reduce remaining substrate and bacterial count in the oral cavity. Moreover, as dental caries is described as infectious and transmissible disease, sharing tooth brush among family members is considered to be one of the horizontal transmission way of cariogenic bacteria [33]. It is recommended for family members to have their own dental utilities, particularly tooth brush.

It is widely known that snacking sugar-containing products is being the major factor as sugar plays an important role on caries initiation process. A review revealed the moderate evidence supporting a positive relationship between sugar consumed and caries development [34]. In contrast, snacking between meals and before bedtime were not significant to caries prevalence in this study. In addition, most of the children were observed for having tooth brushing at least twice a day. This finding may be promoted by a rapid clearance of oral cavity reduces the length of sugar retentiveness time which stimulates acid metabolism by bacteria [35]. A study with similar result explained that this condition might occur due to extensive use of fluoride-containing products, mainly toothpaste [36]. Another review has been mentioned that in the era of adequate fluoride exposure, the relationship between sugar and dental caries is not as strong as before [37]. Moreover, a wide range of fermentable carbohydrates and development of sugar substitutes to be added in food products emphasize the fact that sugar is not a single determinant of caries disease [34]. As long as protective factors are greater than pathological factors in oral environment, the balance process of demineralization and remineralization could be obtained and caries process could be arrested [13].

The demographic and socio-economic factors in this study were not found to be associated with dental caries. Gender, relationship to the child, education level, occupation and family income were not statistically significant. On the other hand, other reviews found that children with lower socio-economics status were at higher risk to develop caries in permanent dentition [15,16]. High socio-economic status was described to give more flexibility to the household in providing oral health utilities and access to health provider and building a good health behavior as well. This association tend to be greater in high income countries than low income countries. Study in Thailand in the $12-15$ years old were found that children with higher family income were at higher risk for caries [21]. A similar finding was reported from Brazil along with parent's educational level and occupation [14]. Sugar consumption was speculated 
http://wjst.wu.ac.th

to be higher in rich countries due to high socio-economic status that would give more availability, while in the developing and underdeveloped countries, it might be income dependent [15,38]. In Japan, mother's oral health behavior and condition were more related to dental caries than other socioeconomics factors because most of the Japanese mothers gradually decreased their attention as the age of children increase [39]. Children over 10 years assumed to start taking responsibility of their behavior. As the literature came from different parts of the world, the political, cultural and other heterogeneity might be an explanation for this differences [15]. The non-uniformity of findings in this field should be noted carefully before generalizing and applying the result into different population.

The examination criteria that be used in this study may be different with other studies, so it is probably demanding to be compared with the results from different countries. However, as the initial study observing the risk factor in early erupted permanent first molars, this study can be useful as the baseline for further research in this field.

\section{Conclusions}

In conclusion, this study confirms the caries vulnerability of permanent first molars in the early stage of eruption among Thai primary schoolchildren. Some related risk factors that were revealed in this age group are brushing at night, sharing tooth brush and having deciduous caries. These children should be longitudinally followed up to determine association of risk factors and caries increment. The high caries prevalence in this age group should be noticed by health professional to take appropriate treatment and preventive measures in order to prevent further progression of its disease.

\section{Acknowledgements}

This work was supported by Graduate School Prince of Songkla University, the Higher Education Research Promotion and the Thailand's Education Hub for Southern Region of ASEAN Countries (TEHAC) Project Office of the Higher Education Commission. We thank the children, school and staff from Hat Yai Hospital for being cooperative and helpful during this research. We also thank Pornpana Suklaaiaad for interviewing the respondents and Dr. Alan Greater from Epidemiology Unit, Faculty of Medicine, Prince of Songkla University for statistical analysis and discussion. The authors declare that there is no conflict of interest.

\section{References}

[1] S Jienmaneechotechai, C Ungchusak, S Dalodom, P Prasertsom and O Matangkasombut. Thailand. In: Proceedings of the International Dental Conference on Caries Control throughout Life in Asia. Krabi, Thailand, 2013, p. 268-86.

[2] M Masood, N Yusof, MIA Hassan and N Jaafar. Assessment of dental caries predictors in 6-yearold school children-results from 5-year retrospective cohort study. BMC Public Health 2012; 12, 989.

[3] RG Watt and PL Rouxel. Dental caries, sugars and food policy. Arch. Dis. Child. 2012; 97, 769-72.

[4] H Seirawan, S Faust and R Mulligan. The impact of oral health on the academic performance of disadvantaged children. Am. J. Public Health 2012; 102, 1729-34.

[5] PA Batchelor and A Sheiham, The distribution of burden of dental caries in schoolchildren: A critique of the high-risk caries prevention strategy for populations. BMC Oral Health 2006; 6, 3.

[6] JC Carvalho. Caries process on occlusal surfaces: Evolving evidence and understanding. Caries Res. 2014; 48, 339-46.

[7] JD Wang, X Chen, J Frencken, MQ Du and Z Chen. Dental caries and first permanent molar pit and fissure morphology in 7-to 8-year-old children in Wuhan, China. Int. J. Dent. Oral. Sci. 2012; 4, 157-60.

[8] JEA Zenkner, LS Alves, RS De Oliveira, RH Bica, MB Wagner and M Maltz. Influence of eruption stage and biofilm accumulation on occlusal caries in permanent molars: A generalized estimating equations logistic approach. Caries Res. 2013; 47, 177-82. 
http://wjst.wu.ac.th

[9] Y Li and W Wang. Predicting caries in permanent teeth from caries in primary teeth: An eight-year cohort study. J. Dent. Res. 2002; 81, 561-6.

[10] B Willershausen, G Haas, F Krummenauer and K Hohenfellner. Relationship between high weight and caries frequency in German elementary school children. Eur. J. Med. Res. 2004; 9, 400-4

[11] VC Marinho, J Higgins, S Logan and A Sheiham. Fluoride toothpastes for preventing dental caries in children and adolescents. Cochrane Database Syst. Rev. 2003; 2003, CD002278.

[12] AM Cooper, LA O'Malley, SN Elison, R Armstrong, G Burnside, P Adair, L Dugdill and C Pine. Primary school-based behavioural interventions for preventing caries. Cochrane Database Syst. Rev. 2013; 2013, CD009378.

[13] JD Featherstone. The continuum of dental caries: Evidence for a dynamic disease process. J. Dent. Res. 2004; 83, C39-C42.

[14] EPDS Tagliaferro, AC Pereira, MDC Meneghim and GMB Ambrosano. Assessment of dental caries predictors in a seven-year longitudinal study. J. Public Health Dent. 2006; 66, 169-73.

[15] F Schwendicke, CE Dörfer, P Schlattmann, LF Page, WM Thomson and S Paris. Socioeconomic inequality and caries a systematic review and meta-analysis. J. Dent. Res. 2015; 94, 10-8.

[16] S Kumar, J Tadakamadla, J Kroon and NW Johnson. Impact of parent-related factors on dental caries in the permanent dentition of 6-12-year-old children: A systematic review. J. Dent. 2016; 46, $1-11$.

[17] JM Broadbent, LF Page, WM Thomson and R Poulton. Permanent dentition caries through the first half of life. Brit. Dent. J. 2013; 215, E12.

[18] LK McCaul, WMM Jenkins and EJ Kay. The reasons for the extraction of various tooth types in Scotland: A 15-year follow up. J. Dent. 2001; 29, 401-7.

[19] I Yavuz, B Baydaş, A İkbal, İM Dağsuyu and I Ceylan. Effects of early loss of permanent first molars on the development of third molars. Am. J. Orthod. Dentofacial. Orthop. 2006; 130, 634-8.

[20] J Lueangpiansamut, S Chatrchaiwiwatana, B Muktabhant and W Inthalohit. Relationship between dental caries status, nutritional status, snack foods, and sugar-sweetened beverages consumption among primary schoolchildren grade 4-6 in Nongbua Khamsaen school, Na Klang district, Nongbua Lampoo Province, Thailand. J. Med. Assoc. Thai 2012; 95, 1090-7.

[21] S Krisdapong, P Prasertsom, K Rattanarangsima and A Sheiham. Sociodemographic differences in oral health-related quality of life related to dental caries in Thai school children. Comm. Dent. Health 2013; 30, 112-8.

[22] S Sutthavong, S Taebanpakul, C Kuruchitkosol, TI Ayudhya, T Chantveerawong, S Fuangroong, S Cae-Ngow and R Rangsin. Oral health status, dental caries risk factors of the children of public kindergarten and schools in Phranakornsriayudhya, Thailand. J. Med. Assoc. Thai 2010; 93, S71S78.

[23] PE Petersen, N Hoerup, N Poomviset, J Prommajan and A Watanapa. Oral health status and oral health behaviour of urban and rural schoolchildren in Southern Thailand. Int. Dent J. 2001; 51, 95102.

[24] S Thitasomakul, S Piwat, A Thearmontree, O Chankanka, W Pithpornchaiyakul and S Madyusoh, Risks for early childhood caries analyzed by negative binomial models. J. Dent. Res. 2009; 88, 13741.

[25] SK Lwanga and S Lemeshow. Sample Size Determination in Health Studies: A Practical Manual. World Health Organization, 1991, p. 1-80.

[26] JC Carvalho, KR Ekstrand and A Thylstrup. Dental plaque and caries on occlusal surfaces of first permanent molars in relation to stage of eruption. J. Dent. Res. 1989; 68, 773-9.

[27] M Addy, P Renton-Harper and G Myatt. A plaque index for occlusal surfaces and fissures: Measurement of repeatability and plaque removal. J. Clin. Periodontol. 1998; 25, 164-8.

[28] C Llena and E Calabuig. Risk factors associated with new caries lesions in permanent first molars in children: A 5-year historical cohort follow-up study. Clin. Oral Investig. 2017; 22, 1579-86.

[29] MS Skeie, M Raadal, GV Strand and I Espelid. The relationship between caries in the primary dentition at 5 years of age and permanent dentition at 10 years of age: A longitudinal study. Int. $J$. Paediatr. Dent. 2006; 16, 152-60. 
[30] RJ Lynch. The primary and mixed dentition, post-eruptive enamel maturation and dental caries: A review. Int. Dent. J. 2013; 63, 3-13.

[31] PE Petersen, J Hunsrisakhun, A Thearmontree, S Pithpornchaiyakul, J Hintao, N Jürgensen and RP Ellwood. School-based intervention for improving the oral health of children in southern Thailand. Comm. Dent. Health 2015; 32, 44-50.

[32] ARF de Castilho, FL Mialhe, TS Barbosa and RM Puppin-Rontani. Influence of family environment on children's oral health: A systematic review. J. Pediatr. 2013; 89, 116-23.

[33] RJ Berkowitz. Mutans streptococci: Acquisition and transmission. Pediatr. Dent. 2006; 28, 106-9.

[34] PJ Moynihan and SAM Kelly. Effect on caries of restricting sugars intake: Systematic review to inform WHO guidelines. J. Dent. Res. 2014; 93, 8-18.

[35] P Gupta, N Gupta, AP Pawar, SS Birajdar, AS Natt and HP Singh. Role of sugar and sugar substitutes in dental caries: A review. ISRN Dentistry 2013; 2013, 519421.

[36] MC Downer, CS Drugan and AS Blinkhorn. Correlates of dental caries in 12-year-old children in Europe: A cross-sectional analysis. Comm. Dent. Health 2008; 25, 70-8.

[37] PA Burt and S Pai. Sugar consumption and caries risk: A systematic review. J. Dent. Educ. $2001 ; 65,1017-23$.

[38] M Siervo, C Montagnese, JC Mathers, KR Soroka, BC Stephan and JC Wells. Sugar consumption and global prevalence of obesity and hypertension: An ecological analysis. Public Health Nutr. 2014; 17, 587-96.

[39] M Okada, M Kawamura, Y Hayashi, N Takase and K Kozai. Simultaneous interrelationship between the oral health behavior and oral health status of mothers and their children. J. Oral Sci. 2008; 50, 447-52. 